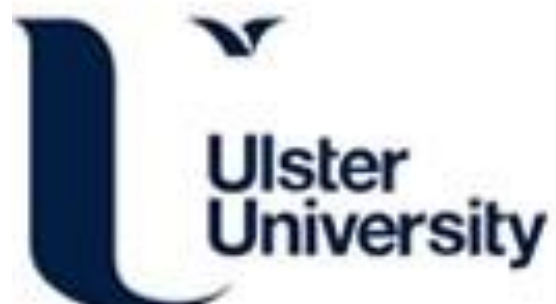

Making numbers count: National datasets on intellectual disability.

McConkey, R., \& Craig, S. (2015). Making numbers count: National datasets on intellectual disability. Tizard Learning Disability Review, 20(1), 24-28. https://doi.org/10.1108/TLDR-10-2014-0032

Link to publication record in Ulster University Research Portal

\section{Published in:}

Tizard Learning Disability Review

Publication Status:

Published (in print/issue): 01/01/2015

DOI:

10.1108/TLDR-10-2014-0032

\section{Document Version}

Author Accepted version

\section{General rights}

Copyright for the publications made accessible via Ulster University's Research Portal is retained by the author(s) and / or other copyright owners and it is a condition of accessing these publications that users recognise and abide by the legal requirements associated with these rights.

\section{Take down policy}

The Research Portal is Ulster University's institutional repository that provides access to Ulster's research outputs. Every effort has been made to ensure that content in the Research Portal does not infringe any person's rights, or applicable UK laws. If you discover content in the Research Portal that you believe breaches copyright or violates any law, please contact pure-support@ulster.ac.uk. 


\title{
Making numbers count: National datasets on intellectual disability
}

\author{
Roy McConkey ${ }^{1}$ and Sarah Craig ${ }^{2}$ \\ ${ }^{1}$ Institute of Nursing and Health Research, University of Ulster \\ 2 National Health Information Systems, Health Research Board, Dublin
}

\author{
Address for Correspondence \\ Professor Roy McConkey \\ Institute of Nursing Research \\ School of Nursing \\ University of Ulster \\ Newtownabbey \\ $\mathrm{N}$ Ireland BT37 0QB
}

Email: r.mcconkey@ulster.ac.uk Phone: 02890852537

Roy McConkey is Emeritus Professor of Developmental Disabilities at the University of Ulster and with colleagues in the Health Research Board has published ten articles in peer-reviewed journals using data from the National Intellectual Disability Database.

Sarah Craig is Head of Information Systems in the Health Research Board which manages the National Intellectual Disability Database on behalf of the Department of Health.

Running Head: Making Numbers Count

Classification of article: Viewpoint/Commentary

Keywords: Intellectual disability, national databases, datasets,

Total word count: 2,564 words

Published as: McConkey, R. \& Craig, S. (2015) Making numbers count: National datasets on intellectual disability. Tizard Learning Disability Review, 20 (1), 24-28. 


\begin{abstract}
Purpose: National datasets on intellectual disability can make a significant contribution to equitable and effective service planning. However major challenges need to be overcome so that the information collected is reliable and valid.

Approach: Drawing on experiences with the National Intellectual Disability Database in Ireland, we identify the key elements to be addressed such as the uses to which information from the database will be put; the definition of intellectual disability for inclusion of individuals; defining the information to be gathered; the systems for gathering information; checking and auditing the information that is collected, and the types of reports emerging from the analyses.

Practical Implications: A national database of persons with an intellectual disability is at least desirable - if not essential - to the delivery of equitable and effective service supports. The advent of computerised data management tools makes this a realistic option in most European countries although debates continue around the protection of personal data and the costs involved in establishing and maintaining dedicated databases.
\end{abstract}

(168 words) 


\section{Why bother counting people?}

Creating a national database of people with an intellectual disability presents many challenges. Yet once created it can serve several important uses for policy-makers and service planners. Firstly a national database will evidence the prevalence of this disability and predict the potential numbers of persons requiring services. Moreover the extent of any regional variation in prevalence rates will be identified. Areas with a higher prevalence deserve greater resources in order to meet the needs in those localities. Variations in prevalence rates within different countries are well documented and this is one of the shortcomings in using locality registers to estimate national data (McConkey et al., 2006).

Secondly a national database can go beyond a simple head count and describe the characteristics of the population in some detail, such as any additional disabilities, present living arrangements, levels of functioning and services received. Such data can help identify inequities in current service provision or be used to bolster the case for new or additional services. However the amount of information sought on each person has to be balanced against the practicalities of obtaining reliable data.

A third contribution but one that is more recent, is to use national datasets to evidence the outcomes for people with an intellectual disability and the impact of new service and support initiatives. To do this effectively, comparisons over time are essential so that changes can be assessed and trends established. This means that the data gathered on people has to be updated regularly - preferably annually - as well as new items being added to the database to reflect new priorities. Thus it may take three or more years before changes over time can be assessed.

A further possible contribution is that a national database provides opportunities for research that is elusive to do otherwise; namely undertaking studies based on total populations rather than with samples, and conducting longitudinal investigations that track the same people over time. These findings can also inform policy and practice.

Implicit in these four functions is a further rationale which is even more crucial in times of austerity. A national database provides an empirical basis for examining differences in service costs and estimating likely costs of new services. This can be crucial in ensuring that people with an intellectual disability receive a fair share of the monies spent by government on health and social care, as well as how the share allocated to this client group is divided up among them. 
In sum, a national database of persons with an intellectual disability is at least desirable - if not essential - to the delivery of equitable and effective service supports. The advent of computerised data management tools makes this a realistic option in most European countries. Nevertheless debates exist around the costs of establishing and maintaining databases plus concerns about the confidentiality of personal information. However the crucial starting point is to be clear on the main purposes for the database; put simply to what uses will the data be put and who will use the information? This will help to determine the information that is gathered, how it is analysed and the way in which the findings are presented. A 'good database' will provide answers to the questions it was designed to provide but it will only do this imperfectly - if at all - for other questions that may arise. Hence a careful cost-benefit assessment is required of the proposed database including the risks of NOT having access to reliable data on service planning. Such judgements are best made by a range of stake-holders: policy-makers, service commissioners and providers plus people with an intellectual disability and their advocates alongside advisers from national statistics bodies familiar with collecting and analysing data. Nevertheless there needs to be scope for changes and for adaptations to the recording of data so as to reflect changes in services and policy.

\section{Creating a national database}

Two approaches are possible. The first is to setup a dedicated database only for persons with an intellectual disability. The second is to extract information on persons with an intellectual disability from existing national datasets (Emerson \& McGrother, 2011). Each has its advantages and disadvantages. A dedicated dataset can be designed to the specific requirements of this client population and their unique needs. However it may not be possible to make comparisons between people with intellectual disabilities and their non-disabled peers. An 'extracted dataset' allows these comparisons to be easily made but on a more limited range of data which is more likely to have been determined by the wider population's needs. It is likely to be less costly than a dedicated data set but there is a greater risk of less reliable data. The reasons for having a national database will help to determine which of these approaches is used.

\section{Who counts as having an intellectual disability?}

Either approach faces the common challenge of defining the people to be counted as having an intellectual disability. The chosen definition clearly affects the numbers of people included in the database as recent studies have shown (Lin et al., 2013; Molden \& 
Trossebro, 2012). Emerson \& Heslop (2010) have attempted to provide a working definition that can be used to extract people with a learning disability from datasets available in the UK. A more pragmatic definition is people who are known to, who avail of or who are deemed to benefit from intellectual disability services. Yet this definition is not without its difficulties if only selected services are covered by the database as is the case in Scotland. The Irish National Database avoids this problem as health, social and educational services are often provided through the same service organisation. Hence the onus is on the database compilers to clearly specify the inclusion and exclusion criteria used for persons recorded on the database. This will identify the limitations to be placed on interpretations of the data. For example, the Scottish data cannot provide prevalence rates for intellectual disability for the country as a whole or across local authority areas.

Data protection issues also arise at this point. It is good practice to obtain people's permission for their inclusion in the database (or from their advocate) although this does not necessarily happen, or need to happen, with extracted datasets. However if people decline to be included then the coverage of the database is reduced and this too needs to be reported. In Ireland, families of preschool children who were still undergoing assessment were reluctant to have their child registered thereby leading to an underrepresentation of this cohort within the national dataset.

Each person registered needs to have a unique identifier. This is used in lieu of names and addresses as a further step in preserving confidentiality but also serves as a check on duplicate entries and enables longitudinal data to be linked on the same individuals over different years. The unique identifier can be specific to the database but there are major benefits to using a national identifier such as a National Health Service number that every UK citizen receives at birth. In Ireland, legislation to provide for an Individual Health Identifier was enacted in July 2014 and when implemented will provide for data linkage opportunities across other national datasets. For example data on GP records and schooling could be linked if there is a common identifier for each person on both datasets. Data linkage reduces the amount of information that has to be collected afresh while widening the extent of information that can be garnered. Unlike other countries, the United Kingdom and Ireland have been slow to exploit the linking of the various datasets held by statutory agencies but this is starting to happen for the wider population and in future may make more information available on persons with intellectual disability (Hussein, 2011). 


\section{Information collected}

Another major consideration is the information to be gathered on each person. A useful maxim is 'less is more'. It is better to have nearly complete information on each person rather than have only some information for some people. The information that is chosen depends on the main purpose of the database and the Scottish dataset contains commonly collected information of relevance to people with an intellectual disability. One curious omission though is the level of functioning of the person. Previous categorisations such as mild, moderate and severe disability are better cast in terms of the levels of support that a person requires in line with modern conceptions of disability (WHO, 2001) which in turn relates to service costs. In Ireland, the national database for people with physical and sensory disability captures outcomes data using a WHO ICF-based measure and the intention is to adapt this measure and add it to the national intellectual disability database as resources allow (O' Donovan \& Doyle, 2006). People's support needs can of course change over time which is a further reason for why the information gathered needs to be regularly updated.

The Scottish data also illustrates the difficulty in obtaining 100\% coverage on some data fields. Various steps can be taken to achieve this goal which is necessary in order to produce valid analyses from the dataset.

Looking ahead a major issue for national datasets is the need to focus more on outcomes for people and not just on the service inputs they receive. Fortunately there is plenty of guidance available on what these might be: from the UN Convention on the Rights of Persons with Disabilities to national surveys of what is important to people with an intellectual disabilities (Iriarte et al., 2014). A short list would include: having paid work, your own home, friends, marital partner and good health. All of which are strikingly similar to the items included on European surveys of quality of life and which would provide an implicit comparison as to how different life for people with an intellectual disability often is (Eurofound, 2012).

\section{Systems for collecting information}

The real test of any database comes with the systems used to gather the information. With national datasets there are likely to be many people involved in gathering the information; usually service personnel such as social workers or key workers. Hence a standard pro forma is usually provided to them in either paper or electronic format on which details for each person is recorded. Ideally the information will be checked with the 
person and/ or their representative and this will be refreshed on a regular basis - usually annually. These records then have to be collated and ideally checked. Experience suggests that this is best done at a more local rather than national level, such as local authorities in UK or for different health service areas as in Ireland. Thus there may be a further layer of people locally who are involved in inputting the information from paper records on to electronic systems or at least checking the information that has been entered by service personnel. Mistakes can be minimised if the electronic system incorporates processes for identifying 'wrong' or illogical information. A final stage involves downloading the suitably anonymised local data into a central database which is usually done at a set point in time. Again personnel are needed at a national level to check these returns and undertake the data analyses. Another key responsibility of theirs is the collation of data across the different years and reporting on trends.

\section{Auditing systems}

With so many different people involved in gathering and collating the data the potential for mistakes is heightened which can range from simple typing errors when entering the data to the use of wrong codes. Validation checks need to be built into the systems at the different levels. Internal comparisons across the various data fields may identify inconsistencies as will major deviations from data recorded in previous years. However periodic audits should be undertaken with a sample of cases recorded on the database and the information held on them is rechecked by repeating the data gathering process. Accuracy rates can then be calculated. For example an audit of the Irish National Database identified $95 \%$ accuracy of the level of support people required in residential settings but this fell to $48 \%$ for recordings of the type of future residential support the person may require (Dodd et al., 2010). These audits will help to improve the definitions used for coding and entering data but also serve as an indicator of the confidence that can be placed in the information reported. Regular audits combined with refresher training for those involved in data entry will serve to improve greatly the quality and accuracy of data.

\section{Reporting}

In our experience the amount of time and effort that goes into gathering national data is rarely matched by the time and effort taken to thoroughly analyse it and reflect on the implications for service planning. Admittedly this final stage often gets left to researchers and statisticians whose fascination with numbers is often not shared by the people making decisions and those advocating for decisions to be made. In part the difficulty is one of 
communication. Statistical reports and articles in learned journals do not make easy reading. In Ireland, local area bulletins are produced annually to mirror the published national data and provide service planners with a profile of their own area. Scotland may show the way in producing more accessible reports to inform not only people with learning disabilities but also the other stakeholders such as politicians who ultimately make funding decisions.

A deeper problem though relates to the 'snap-shot' focus of many reports that contain information gathered at best a year previously but often further back. This lets service planners live with the illusion that things have improved since then. A more powerful approach is to use the datasets to monitor trends over time. Longitudinal analyses not only confirm the consistency in the information gathered but also can reveal whether the intended impact of government policy is being achieved. In Ireland for example, these analyses demonstrated the marked regional variation there was in the move from congregated to community living arrangements (Kelly \& McConkey, 2010). However the basic issue is not the data or even the interpretation of the data but rather identifying the people who will act on the data. Opportunities should be provided for those who work in service planning and delivery to have online access to the data for their own area and to generate their own real time reports.

\section{Looking to the future}

Devising, implementing and improving national databases is a complex task that is made more feasible by advances in computer technology such as online data entry and instant updating of findings. But this comes at a time when concerns about the protection of personal data reduces people's willingness to be included in a database in which they have little control over how their data gets used. At a minimum, people with an intellectual disability and their advocates should be involved in the review and updating of the information held about them on the database. Moreover as people with an intellectual disability become more socially included, they and/or their families may resent the labelling inherent in terms such as 'intellectually disabled'. But these and other debates bring us back to where we started. What common value is there in having a national database that will benefit all the main stake-holders but especially those in need of service supports? 


\section{References}

Dodd, P., Craig, S., Kelly, F. \& Guerin, S. (2010) An audit of the Irish National Intellectual Disability Database. Research in Developmental Disabilities, 31, 446-451

Emerson, E. \& Heslop, P. (2010) A working definition of Learning Disabilities. Lancaster: Improving Health and Lives Learning Disability Observatory.

Emerson, E. \& McGrother, C. (2011) The Use of Pooled Data from Learning Disabilities Registers: A Scoping Review. Lancaster: Improving Health and Lives Learning Disability Observatory.

Eurofound (2013) European Third Quality of Life Survey - Quality of life in Europe: Subjective well-being: Available at http://www.eurofound.europa.eu/publications/htmlfiles/ef1359.htm

Hussein, S. (2012) The use of 'large scale datasets' in UK social care research. London: NIHR School for Social Care Research, London School of Economics and Political Science

Iriarte, E.G., O'Brien, P., McConkey, R., Wolfe, M. \& O'Doherty, S. (2014) Identifying the key concerns of Irish persons with intellectual disabilities. Journal of Applied Research in Intellectual Disabilities, doi: 10.1111/jar.12099.

Kelly, F. \& McConkey, R. (2012) Changes in the provision of residential care for adult persons with an intellectual disability: a national longitudinal study. Tizard Learning Disability Review, 17(1),410.

Lin, E., Balogh, R., Cobigo, V., Ouellette-Kuntz, H., Wilton, A.S. \& Lunsky, Y. (2013) Using administrative health data to identify individuals with intellectual and developmental disabilities: a comparison of algorithms. Journal of Intellectual Disability Research, 57 (5), 462-477.

McConkey, R., Mulvany, F. and Barron, S. (2006) Adult persons with an intellectual disability on the island of Ireland. Journal of Intellectual Disability Research, 50, 227-236

Molden, T.H. \& Trossebro, J. (2012). Disability measurements: impact on research results, Scandinavian Journal of Disability Research, 14 (4), 340-357.

O' Donovan, M-A. and Doyle, A. (2006) Measuring activity and participation of people with disabilities: an overview, MAP Bulletin No. 1, Dublin: Health Research Board.

World Health Organisation (2001) International Classification of Functioning, Disability and Health. http://www.who.int/classifications/icf/en/. 